\title{
The Effectiveness of Temporary Traffic Calming Devices on Reducing Speeds of Traffic Flow in School Zones
}

\author{
Vatanavongs Ratanavaraha ${ }^{1 *}$ and Duangdao Watthanaklang ${ }^{2}$ \\ 'Suranaree University of Technology, Department of Transportation Engineering, 111 University Avenue, \\ Suranaree Sub-district, Nakornratchasima, 30000,Thailand; vatanavongs@g.sut.ac.th \\ 2Suranaree University of Technology, Department of Transportation Engineering, 111 University Avenue, \\ Suranaree Sub-district, Nakornratchasima, 30000, Thailand; D5440320@g.sut.ac.th
}

\begin{abstract}
Safety issue in school zones is one of the momentous problems in Thailand; in which mostly, the passing vehicles are often negligent to decelerate their speeds when entering to school areas. Chiefly, during the schools opening and closing times in a day, a number of students are usually staying in front of such schools. Henceforth, the effort of this study contributes to seek the efficient form of temporary traffic calming device to substantially decrease speeds of traffic flow. The study carried out the examination of three types of temporary traffic calming devices on assumption that they efficiently moderate speeds of traffic flow through the actual test at school zones in Rayong Province where a greater number of accident statistics were recorded. The findings evidently stated that two types of temporary traffic calming devices were suggested in effectively reducing speeds of traffic flow with statistical significance.
\end{abstract}

Keywords: Temporary Traffic Calming Device, Speed Reduction, School Zone Safety, ANOVA

\section{Introduction}

Speed is considered as a meaningful factor to road safety issues. In addition to its subjected influences on accident severity, it can cause the potential risk of accident occurrence. According to the past studies on involving cars, they addressed the relationship between speed and accident rates in the form of exponential function and power function [1]. Regarding Nilsson [11], it was attested more increase in speed, the greater trends of crashes will be. As well, faster speeds are directly associated with level of accident severity. Based on Somchainuek et al.[15], vehicle speed was accounted for $70 \%$ of the leading causes of road accidents in Thailand. In addition, if considering factors that affect crash occurrence based on Clarke et al.[4], it indicated more than $65 \%$ of number of accidents was caused by driving over the speed limit. In parallel, the study of Richter ED [13] relating to speed limit pointed out if the speed limit is raised by $10 \mathrm{~km} / \mathrm{h}$ (from $90 \mathrm{~km} / \mathrm{h}$ to $100 \mathrm{~km} / \mathrm{h}$ ), the number of fatalities on roads will go up to $15 \%$ or increase from $46 \%(90 \mathrm{~km} / \mathrm{h})$ to $61 \%(100 \mathrm{~km} / \mathrm{h})$. Moreover, Hugland et al. [5] also cited that areas - where the speed limit of $90 \mathrm{~km} / \mathrm{h}$ is determined, were found $41 \%$ of drivers who drive over the required speed limit. Therefore, this study endeavors to deter speed rates of passing cars close to the speed limit.

At Intersections in rural areas, severity of crashes is generally greater than urban intersections [6]. Furthermore, the number of accidents on rural roads was larger than on urban ones, especially adolescent group [12]. The study of Liu [10] and Zajac et al.[17] divulged a high- speed driving

* Corresponding author:

Vatanavongs Ratanavaraha (vatanavongs@g.sut.ac.th) 
causes pedestrian accidents at severe level. Khorashadi et al. [8] studied both urban and rural roads in which trucks usually pass, and found that rural roads with truck traffic were considerably found a higher level of crash severity than urban roads. Hence, this study focuses on testing speed deterrence with temporary traffic calming devices.

In school zones, trends of accident occurrence would be elicited since such areas have been entered by students for daily commute to schools during start time $8.00-9.00$ a.m. and finish time $3.00-4.00$ p.m. as peak-times which have demonstrated a significantly greater number of accidents than normal-times [9]. In addition, speed is a major problem of frequent crashes near school zones [7]; accordingly, this research attempts to provide the appropriate forms of temporary traffic calming devices to moderate speeds of the traffic flow in front of schools in rural areas on such peak-times.

\section{Methodology}

This section describes data collection methods, installation practices of temporary traffic calming devices, and methods for analyzing vehicle speed reduction when compared between before and after installing temporary traffic calming devices.

\subsection{Sample Group}

The study applied purposive sampling and selected the study area of rural schools established in adherence to two-lane roads at Rayong Province based on the rationale that when considering accident statistics reports, the Rayong Province showed the greater severity of crashes, in that 148 deaths, 72 serious injuries, and 117 minor injuries from 250 accident cases were recorded in B.E. 2554 (2011) [14].

Sampling was conducted by using laser gun camera to collect the spot speed of passing motorcycles, cars, and trucks. Location of laser gun was designed to install inside the bush to hide it from observation of drivers (if drivers can observe the laser gun, it might affect their speed). The data was gathered in two periods including 07.0008.00 a.m. (school start time) and 03.00-04.00 p.m. (school finish time) with distance of every $50 \mathrm{~m}$. taken totaling about $500 \mathrm{~m}$. (11 points) in the direction of both west bound and east bound. So, total of spot speed is 13,200 times obtained from 1,200 vehicles. According to a sample, it comprises 400 motorcycles, 400 passenger cars, and 400 trucks randomly selected from vehicles passing through survey locations based on 4 cases including no device installed and when installing 3 types of temporary traffic calming devices with 100 samples per case (both east and west sides).

\subsection{Design of Temporary Traffic Calming Devices}

Each type of traffic calming devices was arranged to suit for the traffic calming devices used in temporary basis since school zones are considerably required to reduce speeds on students entering time in the morning and evening. Three types of temporary traffic calming device were applied including:-

1 Type 1: Vertical alignment (only in the center)-encompasses the installation of traffic cone in the mid-street along the center line to reduce speeds as shown in Figure 1.

2 Type 2: Vertical alignment in the center and two roadsides- purposes to narrow the lanes enabling drivers to deter their speed when passing such zone as illustrated in Figure 2.

3 Type 3: Vertical alignment in the center and two roadsides with warning light in the center is the type that provides narrower lanes together with using warning light to provide drivers in adequate seeing spot from far-distance with the aim of road hazard prevention as shown in Figure 3.

\subsection{Analysis of Data}

This research analyzes each pattern of average speed to investigate on whether the efficiency of 3 types of temporary traffic calming devices in reducing speeds of traffic flow is significantly different. One way - ANOVA was applied for comparing any differences among average speed of overall

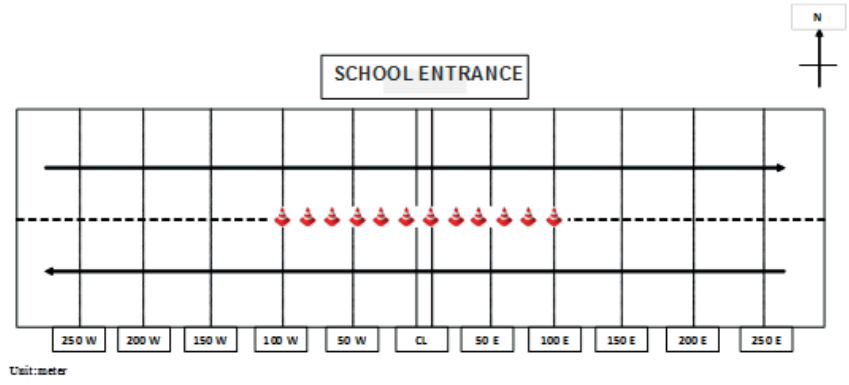

Figure 1. Vertical alignment (only in the center). 


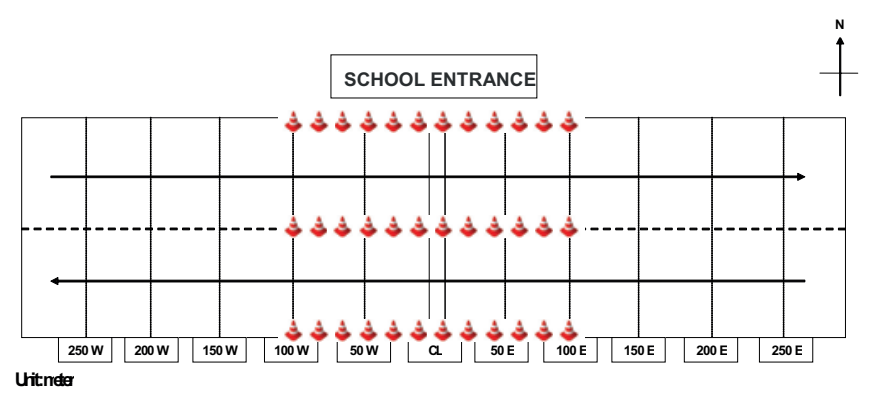

Figure 2. Vertical alignment in the center and two roadsides.

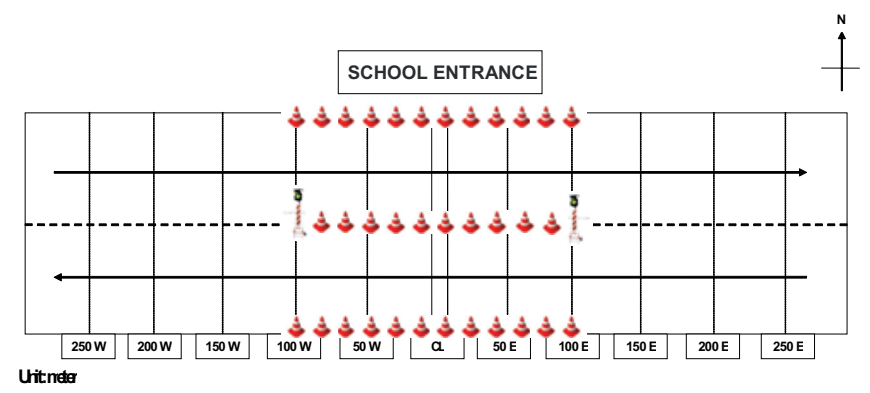

Figure 3. Vertical alignment in the center and two roadsides with warning light in the center.

test based on a statistical F-test. Albeit, the analysis can only be performed to identify the mean differences among group, but not determining on which of the sample pairs are significantly different, so the further test after ANOVA is required including post hoc test with availability of post hoc multiple comparisons regarded as pairwise comparisons.

\section{Findings}

\subsection{Profiles of 85th Percentile Speed of Vehicle}

Based on previous research [16] involving the issues of speed affecting accident occurrence, the $85^{\text {th }}$ percentile speed was prevalently applied for the analysis of vehicle speeds used for gathering data. Hence, this study developed calculation of the $85^{\text {th }}$ percentile speed of each type of vehicles as shown in Figure 4. According to the analysis, the speed profiles found that temporary traffic calming device Type 2 and 3 markedly decrease the speeds of traffic flow when compared to Type 1. The reason for this is that the arrangement style of traffic cones on two roadsides is more likely to enable drivers feel that lanes are narrower [2], and then they have to reduce the vehicle speeds. When

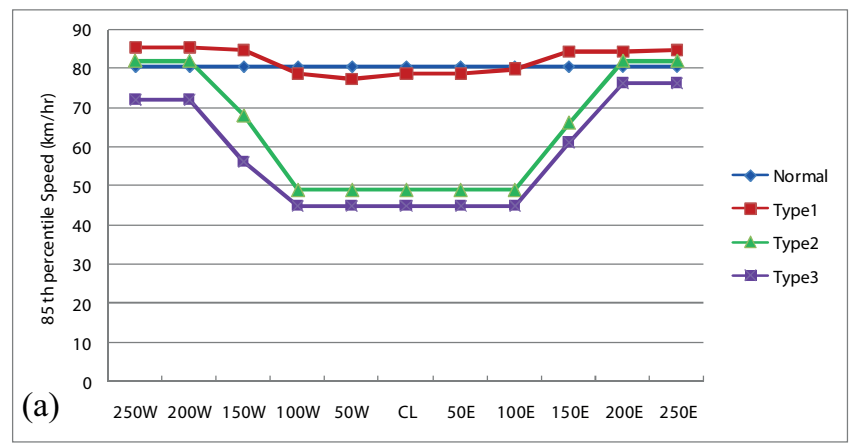

(a) Car in West Bound

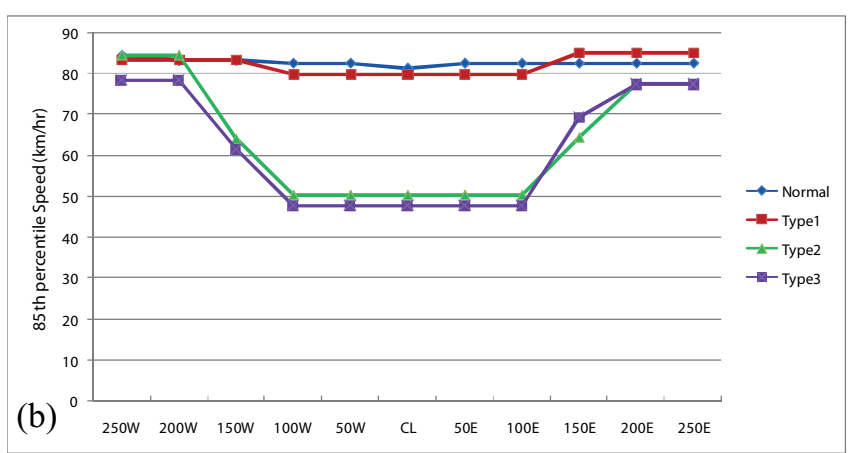

(b) Car in East Bound

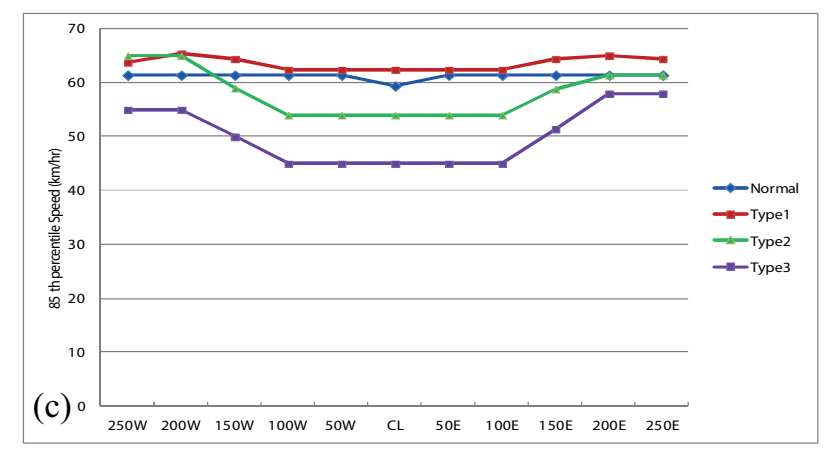

(c) Motorcycle in West Bound

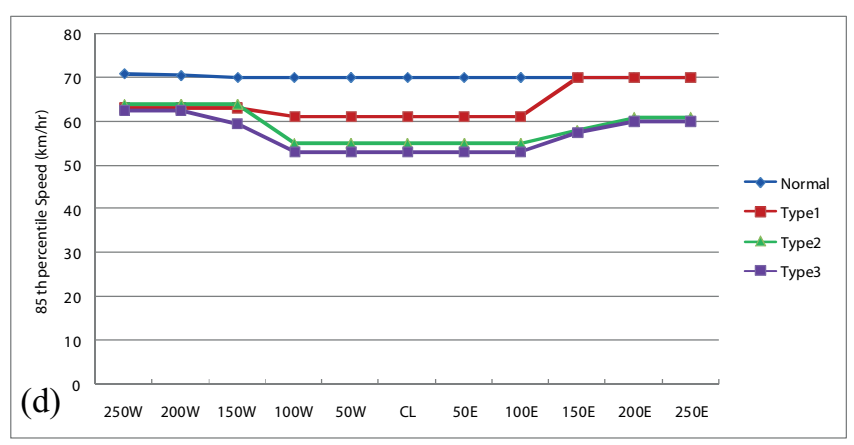

(d) Motorcycle in East Bound 


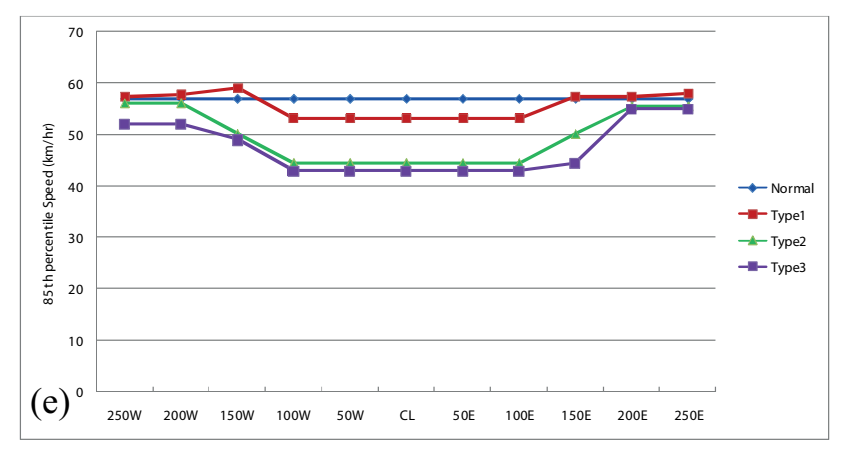

(e) Truck in West Bound

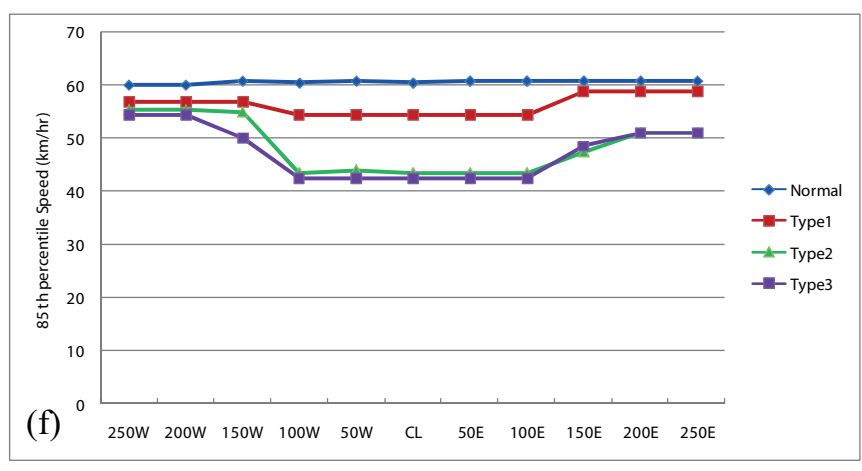

(f) Truck in East Bound

Figure 4. The 85th percentile speed of vehicle.

considering the $85^{\text {th }}$ percentile speed profile, temporary traffic calming device Type 2 and 3 have the greatest effect on the speed reduction of traffic flow of cars, following by trucks; whereas motorcycles are slightly influenced by the use of the devices.

\subsection{Analysis of Speed Differences of Each Type of Temporary Traffic Calming Devices}

Analysis of heterogeneous speed patterns of vehicles passing each type of temporary traffic calming devices was conducted by statistical test of ONE-WAY ANOVA which examines on whether average speed of each type of temporary traffic calming devices is significantly different. It is noted that data used for ANOVA test must have equal variances; therefore, variance test of each data group was carried out with the $95 \%$ confidence level. The hypothesis is denoted as follows:-

$$
\begin{gathered}
\mathrm{H}_{0}: \sigma_{\text {Normal }}^{2}=\sigma_{\text {Type1 }}^{2}=\sigma_{\text {Type } 2}^{2}=\sigma_{\text {Type } 3}^{2} \\
\mathrm{H}_{\mathrm{a}}: \sigma_{i}^{2} \neq \sigma_{j}^{2} \text { at least } 1 \text { pair; } \mathrm{i} \neq \mathrm{j}
\end{gathered}
$$

According to Table 1, the findings of homogeneity of variances test of all types of vehicles are concluded that cars in west bound (at station 250W 200W 200E 250E) and east bound (at station 150W 200E 250E), motorcycles in east bound (at station 250W 200W 150W 200E $250 \mathrm{E}$ ), and trucks in west bound (at station 250W 200W $150 \mathrm{~W} 200 \mathrm{E} 250 \mathrm{E}$ ) and east bound (at station 250W 200W $150 \mathrm{~W}$ ) accept $\mathrm{H}_{0}$. It means that the variances of each type of temporary traffic calming devices at 20 speed points are not different; while in other points, the divergences of variances are considered thus requiring Brown-Forsyth statistical analysis for further test. The next step of variance test uses the following hypothesis for examining means.

$$
\mathrm{H}_{0}: \mu_{\text {Normal }}=\mu_{\text {Type1 }}=\mu_{\text {Type2 }}=\mu_{\text {Type3 }}
$$

$\mathrm{H}_{\mathrm{a}}$ : Average speed of temporary traffic calming devices at least 1 pair is unequal

Regarding Table 2, average speed of trucks passing temporary traffic calming devices at all stations, along with motorcycles in west bound at station $250 \mathrm{~W}-150 \mathrm{E}$ and east bound at station $150 \mathrm{~W}-250 \mathrm{E}$, and trucks in west bound at station $200 \mathrm{~W}-150 \mathrm{E}$ and east bound at all stations has p-value $<0.05$, and then considered in rejecting $\mathrm{H}_{0}$. Thus, it denotes that there is at least 1 pair of means

\begin{tabular}{|c|c|c|c|c|c|c|}
\hline \multirow{3}{*}{ Station } & \multicolumn{6}{|c|}{ West Bound } \\
\hline & \multicolumn{3}{|c|}{ Levene Statistic } & \multicolumn{3}{|c|}{ p-value } \\
\hline & Car & Mc & Truck & Car & Mc & Truck \\
\hline $250 \mathrm{~W}$ & 2.00 & 10.82 & 1.15 & .12 & $.00^{*}$ & .33 \\
\hline $200 \mathrm{~W}$ & 2.11 & 9.84 & 1.12 & .105 & $.00^{*}$ & .35 \\
\hline $150 \mathrm{~W}$ & 6.77 & 13.78 & 2.35 & $.00^{*}$ & $.00^{*}$ & .01 \\
\hline $100 \mathrm{~W}$ & 5.81 & 9.91 & 4.31 & $.00^{*}$ & $.00^{*}$ & $.01^{*}$ \\
\hline $50 \mathrm{~W}$ & 5.47 & 10.83 & 4.87 & $.00^{*}$ & $.00^{*}$ & .00 \\
\hline CL & 7.09 & 10.08 & 5.17 & $.00^{*}$ & $.00^{*}$ & $.00^{*}$ \\
\hline $50 \mathrm{E}$ & 5.79 & 9.87 & 5.18 & $.00^{*}$ & $.00^{*}$ & $.00^{*}$ \\
\hline $100 \mathrm{E}$ & 6.13 & 10.93 & 5.18 & $.00^{*}$ & $.00^{*}$ & $.00^{*}$ \\
\hline $150 \mathrm{E}$ & 3.26 & 8.16 & 4.94 & $.03^{* *}$ & $.00^{*}$ & $.00^{*}$ \\
\hline $200 \mathrm{E}$ & 1.85 & 4.26 & 1.50 & .14 & $.01^{*}$ & .22 \\
\hline $250 \mathrm{E}$ & 1.62 & 4.48 & 1.85 & .19 & $.01^{*}$ & .14 \\
\hline
\end{tabular}
which show differences in reducing speeds or in another

Table 1. Test of Homogeneity of Variances

* Reject $\mathrm{H}_{0}$ when $\mathrm{p}$-value $<0.01$ (statistically significant at $1 \%$ )

${ }^{*}$ Reject $\mathrm{H}_{0}$ when $\mathrm{p}$-value $<0.05$ (statistically significant at $5 \%$ ) 
Table 1. Test of Homogeneity of Variances (Cond't)

\begin{tabular}{|c|c|c|c|c|c|c|}
\hline \multirow{3}{*}{ Station } & \multicolumn{6}{|c|}{ East Bound } \\
\hline & \multicolumn{3}{|c|}{ Levene Statistic } & \multicolumn{3}{|c|}{ p-value } \\
\hline & Car & Mc & Truck & Car & Mc & Truck \\
\hline $250 \mathrm{~W}$ & 3.59 & 1.83 & 1.73 & $.02^{\star *}$ & .15 & .17 \\
\hline $200 \mathrm{~W}$ & 3.14 & 1.58 & 1.66 & $.03^{*}$ & .20 & .18 \\
\hline $150 \mathrm{~W}$ & 1.65 & 2.03 & 1.22 & .18 & .12 & .31 \\
\hline $100 \mathrm{~W}$ & 3.90 & 6.04 & 7.43 & $.01^{\star *}$ & $.00^{*}$ & $.00^{*}$ \\
\hline $50 \mathrm{~W}$ & 3.61 & 5.93 & 8.66 & $.016^{\star}$ & .001 & $.00^{*}$ \\
\hline CL & 5.46 & 8.98 & 9.33 & $.00^{*}$ & $.00^{*}$ & $.00^{*}$ \\
\hline $50 \mathrm{E}$ & 3.41 & 6.19 & 9.43 & $.02^{\star *}$ & $.00^{*}$ & $.00^{*}$ \\
\hline $100 \mathrm{E}$ & 3.79 & 6.19 & 9.43 & $.01^{\star *}$ & $.00^{*}$ & $.00^{*}$ \\
\hline $150 \mathrm{E}$ & 8.64 & 4.87 & 5.04 & $.00^{*}$ & $.00^{*}$ & $.00^{*}$ \\
\hline $200 \mathrm{E}$ & 2.15 & 2.48 & 3.08 & .09 & .06 & $.03^{*}$ \\
\hline $250 \mathrm{E}$ & 2.15 & 2.48 & 3.08 & .09 & .06 & $.03^{*}$ \\
\hline
\end{tabular}

${ }^{*}$ Reject $\mathrm{H}_{0}$ when $\mathrm{p}$-value $<0.01$ (statistically significant at $1 \%$ )

${ }^{*}$ Reject $\mathrm{H}_{0}$ when $\mathrm{p}$-value $<0.05$ (statistically significant at $5 \%$ )

Table 2. ANOVA Test

\begin{tabular}{|c|c|c|c|c|c|c|}
\hline \multirow{3}{*}{ Station } & \multicolumn{6}{|c|}{ West Bound } \\
\hline & \multicolumn{3}{|c|}{$\mathrm{F}$} & \multicolumn{3}{|c|}{$\mathrm{p}$-value } \\
\hline & Car & Mc & Truck & Car & Mc & Truck \\
\hline $250 \mathrm{~W}$ & 13.73 & $2.71^{\mathrm{a}}$ & 5.13 & $.00^{*}$ & .05 & $.00^{*}$ \\
\hline $200 \mathrm{~W}$ & 14.39 & $2.78^{\mathrm{a}}$ & 5.15 & $.00^{*}$ & $.05^{\star *}$ & $.00^{*}$ \\
\hline $150 \mathrm{~W}$ & $112.95^{\mathrm{a}}$ & $16.95^{\mathrm{a}}$ & 19.23 & $.00^{*}$ & $.00^{\star}$ & $.00^{*}$ \\
\hline $100 \mathrm{~W}$ & $377.91^{\mathrm{a}}$ & $46.48^{\mathrm{a}}$ & $62.88^{\mathrm{a}}$ & $.00^{*}$ & $.00^{*}$ & $.00^{*}$ \\
\hline $50 \mathrm{~W}$ & $389.02^{\mathrm{a}}$ & $46.20^{\mathrm{a}}$ & $65.79^{\mathrm{a}}$ & $.00^{*}$ & $.00^{*}$ & $.00^{*}$ \\
\hline $\mathrm{CL}$ & $324.31^{\mathrm{a}}$ & $41.91^{\mathrm{a}}$ & $52.33^{\mathrm{a}}$ & $.00^{*}$ & $.00^{\star}$ & $.00^{\star}$ \\
\hline $50 \mathrm{E}$ & $380.47^{\mathrm{a}}$ & $45.76^{\mathrm{a}}$ & $64.52^{\mathrm{a}}$ & $.00^{*}$ & $.00^{*}$ & $.00^{*}$ \\
\hline $100 \mathrm{E}$ & $353.20^{\mathrm{a}}$ & $46.32^{\mathrm{a}}$ & $64.52^{\mathrm{a}}$ & $.00^{*}$ & $.00^{*}$ & $.00^{*}$ \\
\hline $150 \mathrm{E}$ & $59.64^{\mathrm{a}}$ & $12.60^{\mathrm{a}}$ & $33.70^{\mathrm{a}}$ & $.00^{*}$ & $.00^{\star}$ & $.00^{*}$ \\
\hline $200 \mathrm{E}$ & 4.42 & $1.92^{\mathrm{a}}$ & 2.71 & $.006^{\star}$ & .13 & .05 \\
\hline $250 \mathrm{E}$ & 4.64 & $1.89^{\mathrm{a}}$ & 2.55 & $.005^{\star}$ & .14 & .06 \\
\hline
\end{tabular}

${ }^{a}$ Asymptotically F distributed (Brown-Forsyth)

${ }^{*}$ Reject $\mathrm{H}_{0}$ when $\mathrm{p}$-value $<0.01$ (statistically significant at $1 \%$ )

${ }^{*}$ Reject $\mathrm{H}_{0}$ when $\mathrm{p}$-value $<0.05$ (statistically significant at $5 \%$ )

term, reduction of average speed is relied on types of temporary traffic calming devices.

Table 3 illustrates the results of post hoc multiple comparisons which were used to compare each pair of average speed in west bound and east bound between normal type and 3 types of temporary traffic calming devices. It is based on the assumption that each type of temporary
Table 2. ANOVA Test (Cond't)

\begin{tabular}{|c|c|c|c|c|c|c|}
\hline \multirow{3}{*}{ Station } & \multicolumn{6}{|c|}{ East Bound } \\
\hline & \multicolumn{3}{|c|}{$\mathrm{F}$} & \multicolumn{3}{|c|}{ p-value } \\
\hline & Car & Mc & Truck & Car & Mc & Truck \\
\hline $250 \mathrm{~W}$ & $5.61^{\mathrm{a}}$ & 1.04 & 11.80 & $.00^{*}$ & .38 & $.00^{*}$ \\
\hline $200 \mathrm{~W}$ & $5.81^{\mathrm{a}}$ & .99 & 11.62 & $.00^{\star}$ & .40 & $.00^{*}$ \\
\hline $150 \mathrm{~W}$ & 115.24 & 3.86 & 32.91 & $.00^{*}$ & $.01^{\star *}$ & $.00^{*}$ \\
\hline $100 \mathrm{~W}$ & $321.25^{\mathrm{a}}$ & $18.32^{\mathrm{a}}$ & $94.39^{\mathrm{a}}$ & $.00^{*}$ & $.00^{*}$ & $.00^{*}$ \\
\hline $50 \mathrm{~W}$ & $339.56^{\mathrm{a}}$ & $17.97^{\mathrm{a}}$ & $100.24^{\mathrm{a}}$ & $.00^{*}$ & $.00^{*}$ & $.00^{*}$ \\
\hline $\mathrm{CL}$ & $301.89^{\mathrm{a}}$ & $14.81^{\mathrm{a}}$ & $75.27^{\mathrm{a}}$ & $.00^{*}$ & $.00^{*}$ & $.00^{\star}$ \\
\hline $50 \mathrm{E}$ & $345.04^{\mathrm{a}}$ & $18.39^{\mathrm{a}}$ & $95.63^{\mathrm{a}}$ & $.00^{*}$ & $.00^{*}$ & $.00^{*}$ \\
\hline $100 \mathrm{E}$ & $340.74^{\mathrm{a}}$ & $18.39^{\mathrm{a}}$ & $95.63^{\mathrm{a}}$ & $.00^{\star}$ & $.00^{*}$ & $.00^{\star}$ \\
\hline $150 \mathrm{E}$ & $103.38^{\mathrm{a}}$ & $16.50^{\mathrm{a}}$ & $72.58^{\mathrm{a}}$ & $.00^{\star}$ & $.00^{*}$ & $.00^{*}$ \\
\hline $200 \mathrm{E}$ & 20.93 & 8.86 & $33.56^{\mathrm{a}}$ & $.00^{\star}$ & $.00^{\star}$ & $.00^{\star}$ \\
\hline $250 \mathrm{E}$ & 20.93 & 8.86 & $33.56^{\mathrm{a}}$ & $.00^{*}$ & $.00^{*}$ & $.00^{*}$ \\
\hline
\end{tabular}

${ }^{a}$ Asymptotically F distributed (Brown-Forsyth)

${ }^{*}$ Reject $\mathrm{H}_{0}$ when $\mathrm{p}$-value $<0.01$ (statistically significant at $1 \%$ )

${ }^{*}$ Reject $\mathrm{H}_{0}$ when $\mathrm{p}$-value $<0.05$ (statistically significant at $5 \%$ )

traffic calming devices affects the speed reduction of passing vehicles. The hypothesis is drawn as following:-

$$
\begin{aligned}
& \mathrm{H}_{0}: \mu_{i}=\mu_{j} ; \mathrm{i}=\text { Normal, } \mathrm{j}=\text { Type } 1 \text {, Type } 2 \text {, Type } 3 \\
& \mathrm{H}_{\mathrm{a}}: \mu_{i} \neq \mu_{j} ; \mathrm{i} \neq \mathrm{j}
\end{aligned}
$$

$i$ is the case of no device installed

$\mathrm{j}$ is three types of temporary traffic calming devices

Based on the comparison between average speed of cars, motorcycles, and trucks, the findings found that average speed of all types of vehicles is evidently decreased when using temporary traffic calming device Type 2 and 3 at station $100 \mathrm{~W}-100 \mathrm{E}$ (zones that temporary traffic calming devices were installed) in both west bound and east bound. The comparison test obtains $p$-value $<0.01$, which indicates significant differences; while temporary traffic calming device Type 1 does not influence the speed deterrence of cars and motorcycles, in that the test results represent $p$-value $>0.05$ considered as non-significant difference. However, the device affects the decrease in average speed of trucks at station $100 \mathrm{~W}-100 \mathrm{E}$ in west bound and east bound with $p$-value $<0.01$, thus refers to the significant difference in means.

\section{Discussion and Conclusion}

As regards the study of efficiency in three types of temporary traffic calming devices, the comparison of speed 
Table 3. Post hoc multiple comparisons

\begin{tabular}{|c|c|c|c|c|c|c|c|c|c|}
\hline \multirow{3}{*}{ Sta. } & \multicolumn{9}{|c|}{ Mean Difference (West Bound) } \\
\hline & \multicolumn{3}{|c|}{ CAR } & \multicolumn{3}{|c|}{ Motorcycle } & \multicolumn{3}{|c|}{ Truck } \\
\hline & 1 & 2 & 3 & 1 & 2 & 3 & 1 & 2 & 3 \\
\hline $250 \mathrm{~W}$ & 1.6 & .4 & $-8^{\star *}$ & $-1.2^{\mathrm{t}}$ & $-1.0^{\mathrm{t}}$ & $-4.4^{1 * *}$ & -2.2 & -.8 & $-6.6^{*}$ \\
\hline $200 \mathrm{~W}$ & 2.3 & .6 & $-8.4^{*}$ & $-2^{\mathrm{t}}$ & $-.8^{\mathrm{t}}$ & $-4.2^{t *}$ & -2.2 & -.8 & $-6.6^{*}$ \\
\hline $150 \mathrm{~W}$ & $2.5^{\mathrm{t}}$ & $-11^{t \star}$ & $22.1^{1 *}$ & $-1.3^{\mathrm{t}}$ & $-3.2^{\mathrm{t}}$ & $-9.9^{1 *}$ & -1.6 & $-7.1^{\star}$ & $-8.3^{*}$ \\
\hline $100 \mathrm{~W}$ & $-2.0^{\mathrm{t}}$ & $-30^{*}$ & $-32.9^{1 *}$ & $-2.4^{\mathrm{t}}$ & $-7.1^{\text {t* }}$ & $-14.6^{t *}$ & $-5.8^{\text {t* }}$ & $-13.1^{1 *}$ & $-12.7^{* *}$ \\
\hline $50 \mathrm{~W}$ & $-2.4^{\mathrm{t}}$ & $-30^{1 *}$ & $-32.8^{\text {t* }}$ & $-2.5^{\mathrm{t}}$ & $-7.0^{\mathrm{t} *}$ & $-14.6^{\mathrm{t*}}$ & $-5.7^{\star \star}$ & $-13.1^{t}$ & $-13.1^{\star *}$ \\
\hline CL & $-.8^{\mathrm{t}}$ & $-29 .^{t \star}$ & $-31.8^{\mathrm{t} *}$ & $-1.2^{\mathrm{t}}$ & $-6.1^{\text {t* }}$ & $-13.5^{\text {t* }}$ & $-4.7^{1 * *}$ & $-11.9^{\dagger \star}$ & $-12^{t *}$ \\
\hline $50 \mathrm{E}$ & $-1.9^{\mathrm{t}}$ & $-30.1^{1 *}$ & $-32.9^{t *}$ & $-1.2^{\mathrm{t}}$ & $-6.1^{\mathrm{t} *}$ & $-13.5^{t *}$ & $-5.6^{1 *}$ & $-12.9^{\star *}$ & $-13^{t *}$ \\
\hline $100 \mathrm{E}$ & $-2.0^{\mathrm{t}}$ & $-30^{\mathrm{t} *}$ & $-32.8^{t *}$ & $-2.3^{\mathrm{t}}$ & $-7.2^{\mathrm{t} *}$ & $-14.7^{\text {t* }}$ & $-5.6^{\mathrm{t} *}$ & $-12.9^{t *}$ & $-13^{\text {t* }}$ \\
\hline $150 \mathrm{E}$ & $1.6^{\mathrm{t}}$ & $-13^{t *}$ & $-16.3^{\text {t* }}$ & $-1.6^{\mathrm{t}}$ & $-3.8^{1 * *}$ & $-8.8^{1 \star}$ & $-2.3^{t}$ & $-6.5^{t *}$ & $-11^{1 *}$ \\
\hline $200 \mathrm{E}$ & 1.2 & -.3 & -5.6 & $-1.1^{\mathrm{t}}$ & $-1.7^{\mathrm{t}}$ & $-3.9^{1 * *}$ & -2.9 & -1.2 & -3.5 \\
\hline $250 \mathrm{E}$ & 1.7 & -.2 & -5.4 & $-1.2^{\mathrm{t}}$ & $-1.7^{\mathrm{t}}$ & $-3.9^{t * *}$ & -2.7 & -1.2 & -3.5 \\
\hline
\end{tabular}

'Using Tamhane statistics due to variance differences

${ }^{*}$ Reject $\mathrm{H}_{0}$ when $\mathrm{p}$-value $<0.01$ (statistically significant at $1 \%$ )

${ }^{*}$ Reject $\mathrm{H}_{0}$ when $\mathrm{p}$-value $<0.05$ (statistically significant at $5 \%$ )

Table 3. Post hoc multiple comparisons (Cond't)

\begin{tabular}{|c|c|c|c|c|c|c|c|c|c|}
\hline \multirow{3}{*}{ Sta. } & \multicolumn{9}{|c|}{ Mean Difference ((East Bound) } \\
\hline & \multicolumn{3}{|c|}{ CAR } & \multicolumn{3}{|c|}{ Motorcycle } & \multicolumn{3}{|c|}{ Truck } \\
\hline & 1 & 2 & 3 & 1 & 2 & 3 & 1 & 2 & 3 \\
\hline $250 \mathrm{~W}$ & $2.3^{\mathrm{t}}$ & $-2.6^{\mathrm{t}}$ & $-4.1^{\mathrm{t}}$ & -.2 & $-2.5^{*}$ & -2.4 & -1.7 & $5.5^{*}$ & $-5.6^{*}$ \\
\hline $200 \mathrm{~W}$ & $2.2^{\mathrm{t}}$ & $-2.2^{\mathrm{t}}$ & $-4.4^{\mathrm{t}}$ & .0 & -2.1 & -2.4 & -1.8 & $-5.5^{\star}$ & $-5.7^{\star}$ \\
\hline $150 \mathrm{~W}$ & $2.5^{\mathrm{t}}$ & $-17.4^{\mathrm{t} *}$ & $-17.2^{\text {t* }}$ & -.1 & -2.4 & $-5.6^{*}$ & $-1.4^{\mathrm{t}}$ & $-5.2^{\mathrm{t}}$ & $-10.4^{\mathrm{t} *}$ \\
\hline $100 \mathrm{~W}$ & $-3^{\mathrm{t}}$ & $-31.4^{\mathrm{t}}$ & $-32.9^{t \star}$ & $-2.9^{t}$ & $-8.4^{\mathrm{t*}}$ & $-9.3^{t *}$ & $-6.9^{t *}$ & $-14.5^{\mathrm{t}}$ & $-14.8^{\mathrm{t} *}$ \\
\hline $50 \mathrm{~W}$ & $-3.2^{\mathrm{t}}$ & $-31.4^{t \star}$ & $-32.9^{1 *}$ & $-2.9^{t}$ & $-8.3^{t *}$ & $-9.3^{t *}$ & $-7.4^{t *}$ & $-15^{\text {t* }}$ & $-15.3^{t *}$ \\
\hline CL & $-1.8^{\mathrm{t}}$ & $-30.2^{\text {t* }}$ & $-31.5^{t *}$ & $-1.9^{t}$ & $-7.4^{\mathrm{t} *}$ & $-8.3^{t \star}$ & $-6^{t *}$ & $-13.6^{t *}$ & $-13.9^{t *}$ \\
\hline $50 \mathrm{E}$ & $-3.4^{\mathrm{t}}$ & $-31.7^{\text {t* }}$ & $-33.1^{t *}$ & $-3.0^{\mathrm{t}}$ & $-8.4^{\mathrm{t} *}$ & $-9.4^{\mathrm{t} *}$ & $-7.3^{\text {t* }}$ & $-15^{t \star}$ & $-15.2^{\mathrm{t} *}$ \\
\hline $100 \mathrm{E}$ & -3.2 & $-31.6^{\mathrm{t} *}$ & $-32.9^{t *}$ & $-3^{\mathrm{t}}$ & -8.4 & $-9.4^{\star}$ & $-7.3^{t *}$ & $-15^{\mathrm{t} *}$ & $15.2^{t *}$ \\
\hline $150 \mathrm{E}$ & $3.2^{\mathrm{t}}$ & $-15.6^{t *}$ & $-17.2^{\text {t* }}$ & $3.8^{\mathrm{t}}$ & $5.3^{t * *}$ & $-6.3^{t *}$ & $-1.2^{\mathrm{t}}$ & $-11.4^{t \star}$ & $-11^{t *}$ \\
\hline $200 \mathrm{E}$ & 3.2 & $-5.1^{\star}$ & $-5.8^{\star}$ & 3.8 & -3.6 & -3.8 & $-1.2^{\mathrm{t}}$ & $-8.6^{\mathrm{t} *}$ & $-7.9^{\star}$ \\
\hline $250 \mathrm{E}$ & 3.2 & $-5.1^{\star}$ & $-5.8^{\star}$ & 3.8 & $-3.6^{*}$ & -3.8 & $-1.2^{\mathrm{t}}$ & $-8.6^{t *}$ & $-7.9^{*}$ \\
\hline
\end{tabular}

'Using Tamhane statistics due to variance differences

* Reject $\mathrm{H}_{0}$ when $\mathrm{p}$-value $<0.01$ (statistically significant at $1 \%$ )

** Reject $\mathrm{H}_{0}$ when $\mathrm{p}$-value $<0.05$ (statistically significant at $5 \%$ )

reduction between using devices and normal pattern - at installing points (100 W - $100 \mathrm{E})$ covering a total distance of $200 \mathrm{~m}$., indicated the influences of temporary traffic calming device Type 2 and 3 in decreasing average speed of all vehicle types with statistical significance (p-value $<0.01$ ). Whereas, temporary traffic calming device Type 1 does not have a significant effect on speed deterrence ( $\mathrm{p}$-value $>0.05$ ); nevertheless it significantly affects the reduction of average speed of trucks ( $\mathrm{p}$-value $<0.01$ ).

Concerning assessment of efficiency of temporary traffic calming device Type 2 and 3, it effectively moderates car speeds from $29 \mathrm{~km} / \mathrm{h}-31.76 \mathrm{~km} / \mathrm{h}$ and from 
$31.56 \mathrm{~km} / \mathrm{h}-32.96 \mathrm{~km} / \mathrm{h}$, respectively. Similar to trucks, speed reduction is in the range of $11.96 \mathrm{~km} / \mathrm{h}-15.08 \mathrm{~km} / \mathrm{h}$ (Type 2) and $12.08 \mathrm{~km} / \mathrm{h}-15.36 \mathrm{~km} / \mathrm{h}$ (Type 3). Albeit, the device is able to slightly deter speed in motorcycles, that is, the levels of decrease in speed of motorcycles were ranged from $6.12 \mathrm{~km} / \mathrm{h}-8.48 \mathrm{~km} / \mathrm{h}$ (Type 2) and from $8.32 \mathrm{~km} / \mathrm{h}$ $13.72 \mathrm{~km} / \mathrm{h}$ (Type 3), which have the greater values when compared to previous studies that applied temporary traffic sign and portable changeable message sign (PCMS) in construction work. The past results indicated the effective of two devices in reducing car speeds equals to $4.54 \mathrm{~km} / \mathrm{h}$ and 2.55 $\mathrm{km} / \mathrm{h}$, respectively. While temporary traffic sign has perceivably impacts on speed reduction in trucks of $2.10 \mathrm{~km} / \mathrm{h}$ when compared to portable changeable message sign [3].

The application of temporary traffic calming devices provides the capability of speed reduction of traffic flow in school zones; especially the device Type 2 and 3 are able to decrease average speed of all types of vehicles with similar efficiency, or possible substitution among both types. As well, the device Type 1 is more likely to be applied for reducing truck speeds. In addition, the devices are also appropriately used in school zones where reduction of speeds is considerably required in some periods of time. Therefore, when the device Type 2 and 3 are acquired for the application of decreasing average speed of vehicles, the significant reduction of speeds is greatly existed (p-value $<0.01$ ).

\section{Acknowledgements}

The authors would like to thank Mitsui Sumitomo Insurance Welfare Foundation and Suranaree University of Technology (SUT) for the funding of this research project. We also thank the students and staff at SUT for their continual support in various aspects related to data collection, management, and analyses to complete the study.

\section{References}

1. Aarts L, and Van Schagen I (2006). Driving speed and the risk of road crashes: A review, Accident Analysis \& Prevention, vol 38(2), 215-224.

2. Allpress J A, and Leland L S (2010). Reducing traffic speed within roadwork sites using obtrusive perceptual countermeasures, Accident Analysis \& Prevention,vol 42(2), 377-383.
3. Bai Y, Finger K et al. (2010). Analyzing motorists' responses to temporary signage in highway work zones, Safety Science, vol 48(2), 215-221.

4. Clarke D D, Ward P et al. (2010). Killer crashes: Fatal road traffic accidents in the UK, Accident Analysis \& Prevention, vol 42(2), 764-770.

5. Haglund M, and Aberg L (2000). Speed choice in relation to speed limit and influences from other drivers, Transportation Research Part F: Traffic Psychology and Behaviour, vol 3(1), 39-51.

6. Haleem K, and Abdel-Aty M (2010). Examining traffic crash injury severity at unsignalized intersections. Journal of Safety Research, vol 41(4), 347-357.

7. Kattan L, Tay R et al. (2011). Managing speed at school and playground zones. Accident Analysis \& Prevention, vol 43(5), 1887-1891.

8. Khorashadi A, Niemeier D et al. (2005). Differences in rural and urban driver-injury severities in accidents involving large-trucks: An exploratory analysis, Accident Analysis \& Prevention, vol 37(5), 910-921.

9. Kingham S, Sabel C E et al. (2011). The impact of the 'school run' on road traffic accidents: A spatio-temporal analysis, Journal of Transport Geography, vol 19(4), 705-711.

10. Liu B-S (2007). Association of intersection approach speed with driver characteristics, vehicle type and traffic conditions comparing urban and suburban areas, Accident Analysis \& Prevention, vol 39(2), 216-223.

11. Nilsson G (2004). Traffic safety dimensions and the power model to describe the effect of speed on safety, Nationnal Road Adiministration and Nation Road and Transport Research Institute, vol 221.

12. Peek-Asa C, Britton C et al. (2010). Teenage driver crash incidence and factors influencing crash injury by rurality, Journal of Safety Research, vol 41(6), 487-492.

13. Richter E D, Friedman L et al. (2004). Raising the speed limit by $10 \mathrm{~km} / \mathrm{h}$ significantly increases the number of people killed in road accidents, Evidence-Based Healthcare and Public health, vol 8(5), 268-269.

14. Royal Thai Police (2011). Road accident in thailand report 2011, Central Information Technology Center.

15. Somchainuek O, Taneerananon $P$ et al.(2013). Investigation into Roadside Safety on Thai National Highways, Indian Journal of Science and Technology, vol 6(1), 3923-3927.

16. Woolley J E, Dyson C B et al. (2002). Impacts of lower speed limits in South Australia. Iatss Research, vol 26(2), 6-17.

17. Zajac S S, and Ivan J N (2003). Factors influencing injury severity of motor vehicle-crossing pedestrian crashes in rural Connecticut, Accident Analysis \& Prevention, vol 35(3), 369-379. 